\title{
Dental Students' Knowledge, Attitudes and Beliefs Regarding Molar Incisor Hypomineralization (MIH): A Survey in Vienna, Austria
}

\author{
Katrin Bekes iD \\ Kaya Melichar \\ Tanja Stamm² \\ Karim Elhennawy ${ }^{3}$ \\ 'Department of Paediatric Dentistry, \\ University Clinic of Dentistry, Medical \\ University of Vienna, Vienna, Austria; \\ ${ }^{2}$ Center for Medical Statistics, Informatics, \\ and Intelligent Systems, Medical University \\ of Vienna, Section for Outcomes Research, \\ Vienna, Austria; ${ }^{3}$ Department of \\ Orthodontics, Dentofacial Orthopedics and \\ Pedodontics, Charité - Universitätsmedizin \\ Berlin, Berlin, Germany
}

Purpose: Molar incisor hypomineralization $(\mathrm{MIH})$ is a frequently encountered dental condition worldwide. The aim of this study was to evaluate the knowledge of Austrian dental students about MIH.

Methods: A validated paper-based survey was distributed among 100 final year dental students at the Medical University of Vienna to assess their knowledge, perception and believes regarding MIH. One hundred dental students at the University Dental Clinic of Vienna were included in the study. At the time of the survey, they were in their 11th or 12th semester (final year). Information about the knowledge on diagnosis and prevalence, and attitudes and beliefs around etiology and management was collected.

Results: All students replied, 94 questionnaires could be included in the analysis $(50 \%$ female). $98 \%$ of the students were familiar with MIH and $86 \%$ were aware with the clinical features of MIH. Only 13\% reported clinical ability to identify MIH. Regarding the etiology of MIH, most of the students (69\%) named "genetic factors" as the most frequent etiological factor.

Conclusion: Dental students showed great interest in the topic of $\mathrm{MIH}$, as the majority of all respondents were in favor of deepening their knowledge regarding this topic. The students should be offered opportunities to do this both during and after their studies.

Keywords: molar incisor hypomineralization, MIH, students, knowledge, beliefs, attitudes

\section{Introduction}

The big range of the worldwide prevalence of molar incisor hypomineralization (2$40 \%$ worldwide $)^{1-3}$ and the increasingly research interest of MIH makes this entity one of the most important topics in modern dentistry. It is defined as enamel hypomineralization of systemic origin affecting one or more first permanent molars that are associated frequently with affected incisors. ${ }^{4}$ The etiology of $\mathrm{MIH}$ is not clear yet, theories such as illness during pregnancy, premature or prolonged birth, childhood illness (in the first year of life) and others like vitamin D deficiency and Bisphenol A are being discussed. ${ }^{5-10}$ MIH affected enamel differs both, morphologically and histologically in comparison to healthy enamel. ${ }^{11}$ The enamel is characterized by decreased mechanical properties, mineral density and an increased protein content. ${ }^{11}$ Clinically, MIH ranges from creamy/white through yellow to brown color changes with or without enamel post-eruptive breakdown (PEB). ${ }^{12,13}$ The presence of such lesions in the aesthetic zone and/or the fact that they can be hypersensitive negatively affects the child's oral health-related quality of life. ${ }^{14-16}$
Correspondence: Katrin Bekes Department of Pediatric Dentistry, University Clinic of Dentistry, Medical University of Vienna, Sensengasse 2a, Vienna, 1090, Austria

Tel +43-I-40070280I

Fax +43-I-400702809

Email katrin.bekes@meduniwien.ac.at 
As MIH may be mistaken for a range of other conditions, it is essential to distinguish between MIH and other abnormalities in the dental structures. Judgement criteria include the presence of demarcated opacities, posteruptive enamel breakdown, atypical restorations, extraction of molars due to MIH or failure of eruption of a molar or an incisor. To diagnose MIH, at least one FPM has to be affected. ${ }^{17}$

The management of MIH is challenging as the clinical appearance and individual need for treatment varies widely. Available treatment modalities are extensive, ranging from prevention, restoration, to extraction. ${ }^{18}$ The suitability of these, however, differs depending on a number of factors. Commonly identified factors are severity of the condition (eg extent of the defective enamel and quality of both, defective enamel and unaffected parts of the tooth), presence of symptoms (with or without association of hypersensitivity), patient's dental age and child/parent's social background and expectation. ${ }^{19}$ The decision as to which of these options is suitable needs to be made individually.

MIH has a significant burden on patients and their caregivers and is also a challenge for most practitioners. In order to determine the recognition of MIH as a common condition and as a significant clinical problem, several questionnaire-based studies on the awareness, knowledge, and perceptions of dental health care providers regarding $\mathrm{MIH}$ have been conducted in many countries, ${ }^{20-24}$ showing that there was confusion about the prevalence, etiology, and treatment options for MIH. Until now, there are only extremely sparse data on dental students' knowledge. So far, this topic was only investigated in Australia, ${ }^{25}$ Germany, ${ }^{26}$ and in Saudi Arabia. ${ }^{27}$ In Austria, no studies have been conducted yet.

Therefore, this study aimed to assess the clinical knowledge and perception regarding the distribution, severity, etiology and treatment modalities of MIH in final year (11th and 12th semester) dental students at the biggest Austrian dental school (Medical University of Vienna).

\section{Materials and Methods Study Design}

A survey of dental students at the Medical University of Vienna who were in their final year (11th and 12th semester) was conducted. A paper-based questionnaire was used to assess Vienna dental students' knowledge, perception and believes regarding MIH. This questionnaire was already validated and applied in a similar study in Germany. ${ }^{26}$ Further similar surveys were published before ${ }^{23,28,29}$ and served as a template for our questionnaire (Appendix 1). The questionnaire was piloted among five test persons regarding the phrasing of the questions. To our knowledge, Austrian data are not published yet.

In Austria, a survey among experts is the only type of research involving humans that does not need an ethics approval. The internal data protection committee of the Medical University of Vienna is responsible for surveys among employees and students at the university. Approval for this study was given. Reporting follows the STROBE checklist (Appendix 2). ${ }^{30}$

\section{Setting, Participants, Sample Size}

One hundred dental students at the University Dental Clinic of Vienna which were randomly chosen were included in the study. At the time of the survey, they were in their 11th or 12th semester (final year of a six years programme). Lower semesters were excluded. The paper-based questionnaire was given personally to all study participants. A total of 100 questionnaires were distributed. The students were asked to fill out this questionnaire and return it to a locked box with a thin opening at the top. All (100\%) questionnaires were returned. Before the statistical evaluation, all data records were checked for completeness in order to eliminate unnecessary response errors in advance. All data records were transferred to an Excel table.

\section{Data Sources and Variables (Questionnaire)}

Data were collected between June and August 2019. We used a validated questionnaire-based survey in German language in this study that was already applied in a similar study in Germany. ${ }^{26}$ The survey comprised a series of 18 multiple-choice questions and a cover letter that summarized the aim of the study, briefly described MIH and showed clinical photographs of hypomineralized permanent molars and incisors as well as second deciduous molars. The first section focused on demographic data (age, gender, students' semester), the second section assessed the knowledge and attitudes (diagnosis and clinical presentation) and the final section concentrated on the prevalence and beliefs towards management and educational needs. 


\section{Statistical Analysis}

This study was part of the "Knowledge Project of MIH in Vienna" focusing on students'and dentists' knowledge. Based on the data already available from GambettaTessini, ${ }^{21}$ a power of $80 \%$, an assumed significance level of $5 \%$, the sample size estimate results in a necessary total number of $\mathrm{n}=100$ subjects per group. Therefore, 100 students were approached to take part in the survey.

Only completed questionnaires were included in the analysis. Categorical data were processed using descriptive statistics and, if possible and useful, using the $\mathrm{Chi}^{2}$ test. Absolute and relative frequencies of the answer options were calculated for the individual questions and presented in tabular form. The significance level was set to $\mathrm{p}=0.05$. Univariate analysis methods were used. Calculations were done with $\mathrm{R}$ version 3.6.1.

\section{Results}

From the 100 students who were invited to participate, all replied. Six surveys were eliminated because they were not completed, resulting in a response rate of $94 \%$ (50\% of the participants were female). At the time of the survey, 20 students $(21 \%)$ were in their 11 th semester and 74 students $(79 \%)$ in their 12th semester (Table 1).

The majority $(98 \%, n=92)$ of the students were familiar with MIH. $88 \%(\mathrm{n}=81)$ stated that they had already heard of MIH in lectures, and $73 \%(n=67)$ reported that they were confronted with the topic of MIH in dental clinic courses (Table 1).

Most students were familiar with the clinical features of MIH (86\%), however, only $23 \%(\mathrm{n}=18)$ knew how to implement them. Furthermore, only 13\% reported clinical ability to identify MIH (Table 1). Regarding confidence of diagnosing $\mathrm{MIH}, 5 \%$ reported being confident, followed by $86 \%$ being slightly confident. Moreover, $77 \%$ of the students answered having difficulties distinguishing $\mathrm{MIH}$ from other developmental defects, especially amelogenesis imperfecta $(72 \%, \quad n=54)$ or enamel hypoplasia $(68 \%, \mathrm{n}=49)$.

Regarding the etiology of MIH, most of the students $(69 \%, n=65)$ named "genetic factors" as the most frequent etiological factor, followed by "chronic illness of the affected child" with $22 \%(\mathrm{n}=21)$ (Table 2).

Only $32 \%(n=30)$ of the study participants were certain that they knew the prevalence of MIH in Austria, but the majority $(94 \%, n=88)$ answered that it was worth investigating this further.
Approximately one quarter of the students $(23 \%, \mathrm{n}=22)$ believed they were able to diagnose patients with $\mathrm{MIH}$, from which $91 \%(n=20)$ were in their 12th semester.

A total of $19 \%(n=18)$ students had observed MIH in fewer than approximately $10 \%$ of their patients and $<1 \%$ $(n=4)$ in more than $25 \%$ of their patients. Yellow/brown demarcated lesions and post-eruptive enamel breakdown were the most common defects seen by the students (Table 1).

When asked about the choice of material regarding treatment of MIH molars, $59 \%(n=13)$ of the students decided to use composite. Amalgam was not mentioned by any of the participants (Table 2). Approximately twothirds $(64 \%, n=14)$ of the students claimed that the "durability" factor influences mostly their choice of restorative material.

Nearly all students $(91 \%, \mathrm{n}=20)$ acknowledged $\mathrm{MIH}$ as a clinical problem, for almost two-thirds $(64 \%, n=14)$ of them, the long-term success of the restorations was challenging.

The majority of the students from the 11th semester $(90 \%, \mathrm{n}=18)$ and from the 12th semester $(97 \%, \mathrm{n}=72)$ suggested that the subject should be included in more detail in the dental curriculum. Students in their 12th semester were significantly more familiar with MIH and its prevalence in Austria ( $\mathrm{p}=0.01$, Chi Square Test), compared to students in the 11th semester.

\section{Discussion}

In this study, we explored the knowledge and assessment of Austrian last year dental students with regard to MIH. This condition is a widely recognized condition and presents significant clinical problems for the majority of patients, particularly difficulties in providing high quality restorative care.

In order to be able to assess the extent of the teaching needs in the field of MIH, it is important to determine the current state of knowledge in this regard. Particular attention was given to this topic in in different countries, including Australia, New Zealand, Kuwait, Chile, Hong Kong, Saudi Arabia, Ireland, UK, Spain and Germany. ${ }^{20-24,27-29,31-33}$ Most of these studies were of cross-sectional nature and dealt with the perception and knowledge of dentists (general dentists and specialized ones) about MIH, only the studies done in Australia, Saudi Arabia and Germany reported students' knowledge of this topic. ${ }^{25-27}$ 
Table I Students' Responses on Knowledge, Attitudes and Believes Toward MIH Diagnosis and Prevalence

\begin{tabular}{|c|c|c|c|c|}
\hline \multirow[t]{2}{*}{ Question } & \multirow{2}{*}{$\begin{array}{l}\text { Total Response } \\
\text { Rate }\end{array}$} & \multicolumn{3}{|c|}{ Percentage Distribution of Positive Answers } \\
\hline & & $\begin{array}{l}\text { All Students } \\
(\mathbf{N}=94)\end{array}$ & $\begin{array}{l}\text { I I th Semester } \\
(\mathrm{N}=\mathbf{2 0})\end{array}$ & $\begin{array}{l}\text { I2th Semester } \\
(\mathrm{N}=74)\end{array}$ \\
\hline \multicolumn{5}{|l|}{ Are you familiar with MIH? } \\
\hline & $98 \%$ & $92(98 \%)$ & $2(10 \%)$ & 28 (38\%)* \\
\hline \multicolumn{5}{|l|}{ How did you hear about it? } \\
\hline Dental journals & & $13(14 \%)$ & $6(32 \%)$ & $7(10 \%)$ \\
\hline Lectures & & 81 (88\%) & 15 (79\%) & $66(90 \%)$ \\
\hline Lecture notes & & $35(38 \%)$ & $8(42 \%)$ & $27(37 \%)$ \\
\hline Brochures or pamphlets & & $6(7 \%)$ & $0(0 \%)$ & $6(8 \%)$ \\
\hline Internet & & $23(25 \%)$ & $9(47 \%)$ & 14 (19\%)* \\
\hline Books & & $17(18 \%)$ & $5(26 \%)$ & $12(16 \%)$ \\
\hline Dental clinic & & $67(73 \%)$ & $13(68 \%)$ & $54(74 \%)$ \\
\hline Other students & & $8(9 \%)$ & I (5\%) & $7(10 \%)$ \\
\hline \multicolumn{5}{|l|}{ Do you know the clinical features of MIH? } \\
\hline & $86 \%$ & 81 (86\%) & 15 (79\%) & $66(90 \%)$ \\
\hline \multicolumn{5}{|c|}{ Do you know if there are clinical criteria to diagnose MIH? } \\
\hline Yes, and I know how to implement them & $23 \%$ & $18(82 \%)$ & I (50\%) & 17 (85\%) \\
\hline $\begin{array}{l}\text { Yes, but I do not know how to implement } \\
\text { them }\end{array}$ & $23 \%$ & $4(18 \%)$ & I (50\%) & $3(15 \%)$ \\
\hline \multicolumn{5}{|c|}{ In clinic, do you know if you can identify a patient with MIH? } \\
\hline Yes & $23 \%$ & $12(13 \%)$ & $2(10 \%)$ & $10(27 \%)$ \\
\hline Not sure & $57 \%$ & $54(57 \%)$ & $12(60 \%)$ & $42(57 \%)$ \\
\hline \multicolumn{5}{|c|}{ How confident do you feel when diagnosing MIH? } \\
\hline Very confident & & - & - & - \\
\hline Confident & $23 \%$ & I (5\%) & - & I (5\%) \\
\hline Slightly confident & & $19(86 \%)$ & $2(100 \%)$ & 17 (85\%) \\
\hline Not confident at all & & $2(9 \%)$ & - & $2(10 \%)$ \\
\hline \multicolumn{5}{|c|}{ Do you have difficulty distinguishing MIH as a developmental defect of enamel that differs from other tooth conditions? } \\
\hline & $77 \%$ & $72(77 \%)$ & $12(80 \%)$ & $60(81 \%)$ \\
\hline \multicolumn{5}{|l|}{ Which ones? } \\
\hline Dental fluorosis & $77 \%$ & $18(25 \%)$ & $3(20 \%)$ & $15(26 \%)$ \\
\hline Enamel hypoplasia & & $49(68 \%)$ & $8(53 \%)$ & $4 \mid(72 \%)$ \\
\hline Amelogenesis imperfecta & & $52(72 \%)$ & $12(80 \%)$ & $40(70 \%)$ \\
\hline Dentinogenesis imperfecta & & II (15\%) & $3(20 \%)$ & $8(14 \%)$ \\
\hline \multicolumn{5}{|c|}{ Are you aware of the prevalence of MIH in Austria? } \\
\hline & $32 \%$ & $30(32 \%)$ & $2(10 \%)$ & $28(38 \%)^{*}$ \\
\hline \multicolumn{5}{|c|}{ Do you think it would be worthwhile investigating the prevalence in Austria? } \\
\hline & $94 \%$ & $88(94 \%)$ & $18(90 \%)$ & $70(95 \%)$ \\
\hline
\end{tabular}

(Continued) 
Table I (Continued).

\begin{tabular}{|c|c|c|c|c|}
\hline \multirow[t]{2}{*}{ Question } & \multirow{2}{*}{$\begin{array}{l}\text { Total Response } \\
\text { Rate }\end{array}$} & \multicolumn{3}{|c|}{ Percentage Distribution of Positive Answers } \\
\hline & & $\begin{array}{l}\text { All Students } \\
(\mathbf{N}=94)\end{array}$ & $\begin{array}{l}\text { I I th Semester } \\
(\mathbf{N}=\mathbf{2 0})\end{array}$ & $\begin{array}{l}\text { I 2th Semester } \\
(\mathbf{N}=\mathbf{7 4})\end{array}$ \\
\hline \multicolumn{5}{|c|}{ How often do you notice these teeth in clinic? } \\
\hline Monthly basis & $23 \%$ & $3(14 \%)$ & - & $3(15 \%)$ \\
\hline Yearly basis & & $19(86)$ & $2(100 \%)$ & $17(85 \%)$ \\
\hline \multicolumn{5}{|c|}{ In what proportion of patients do you observe MIH teeth? } \\
\hline$<10 \%$ & $23 \%$ & $18(82 \%)$ & $2(100 \%)$ & $16(80 \%)$ \\
\hline $10-25 \%$ & & $4(18 \%)$ & - & $4(20 \%)$ \\
\hline \multicolumn{5}{|c|}{ Which of the following features do you most frequently notice regarding severity of the defect? } \\
\hline White demarcation & $23 \%$ & $2(9 \%)$ & - & $2(10 \%)$ \\
\hline Yellow/brown demarcation & & II (50\%) & $2(100 \%)$ & $9(45 \%)$ \\
\hline Post-eruptive enamel breakdown & & $9(41 \%)$ & - & $9(45 \%)$ \\
\hline \multicolumn{5}{|c|}{$\begin{array}{l}\text { In clinic, have you encountered demarcated hypomineralized defects in permanent teeth other than the first permanent molars } \\
\text { and incisors? }\end{array}$} \\
\hline & $6 \%$ & $6(27 \%)$ & - & $6(30 \%)$ \\
\hline \multicolumn{5}{|l|}{ Name the tooth/teeth } \\
\hline Canines & $3 \%$ & $3(14 \%)$ & & $3(15 \%)$ \\
\hline Premolars & & $3(14 \%)$ & & $3(15 \%)$ \\
\hline \multicolumn{5}{|c|}{$\begin{array}{l}\text { How frequently do you notice demarcated hypomineralized lesions in the second primary molar tooth in comparison to the first } \\
\text { permanent molar tooth? }\end{array}$} \\
\hline More frequently & $23 \%$ & - & - & - \\
\hline Less frequently & & $9(4 \mid \%)$ & - & $9(45 \%)$ \\
\hline The same as for the first permanent molar & & I (5\%) & - & I (5\%) \\
\hline Never seen it & & $12(55 \%)$ & $2(100 \%)$ & $10(50 \%)$ \\
\hline
\end{tabular}

Note: Significant differences between IIth and I2th semester $(P<0.05$, Chi-squared test $)$ are indicated in bold*.

In Saudi Arabia 43\% dental students from the 4th year and $28 \%$ of the dental students from the 5 th year had heard of $\mathrm{MIH}$, in Germany these percentages were $95 \%$ and $99 \%{ }^{26,27}$ In our study, $95 \%$ of the Austrian students from the 11 th semester and $98.6 \%$ of the students from the 12th semester reported there were familiar with MIH. The agreement with Germany and the non-agreement with Saudi Arabia may be related to the different years of application of the questionnaire. In Saudi Arabia the study was conducted in 2016, in Germany 4 years later. In all countries, university lectures were the highest ranked source of information on MIH (66-90\%). It is interesting that in all three studies approximately a quarter (16-26\%) of the students obtained their information about MIH from books. There were significant differences between the two studies in terms of knowledge of the clinical characteristics of $\mathrm{MIH}$ which might also be explained by the different time points of the conduction of the study. Between $25 \%$ and $35 \%$ of students at King Saud University in Riyadh knew about the clinical features of MIH. In contrast, $86 \%$ of the students at the Medical University of Vienna stated that they knew about the clinical presentation of MIH. This was in agreement with German students reporting similar results. Most of the students from all studies did not trust themselves to make a diagnosis (55-67\%). Only between $1.5 \%$ and $4.9 \%$ of dental students from Saudi Arabia knew the clinical criteria for diagnosing MIH and how to apply them practically. In Austria, 5\% of the 11th semester students reported they knew the clinical criteria for diagnosing MIH, however, $16.2 \%$ of the 12 th semester students knew how to use the clinical criteria to diagnose MIH. More than two-thirds dental students at King Saud University had encountered 
Table 2 Knowledge, Attitudes and Beliefs on Etiology, Management and Education Need of Students Towards MIH

\begin{tabular}{|c|c|c|c|c|}
\hline \multirow[t]{2}{*}{ Question } & \multirow{2}{*}{$\begin{array}{l}\text { Total } \\
\text { Response } \\
\text { Rate }\end{array}$} & \multicolumn{3}{|c|}{ Percentage Distribution of Positive Answers } \\
\hline & & $\begin{array}{l}\text { All Students } \\
(\mathrm{N}=94)\end{array}$ & $\begin{array}{l}\text { I I th } \\
\text { Semester } \\
(\mathrm{N}=\mathbf{2 0})\end{array}$ & $\begin{array}{l}\text { I2th } \\
\text { Semester } \\
(\mathrm{N}=74)\end{array}$ \\
\hline \multicolumn{5}{|l|}{ Which factor(s) do you think are involved in the etiology of MIH? } \\
\hline $\begin{array}{l}\text { Genetic factors } \\
\text { Chronic medical condition(s) that affect the mother during pregnancy } \\
\text { Chronic medical condition(s) that affect the involved child } \\
\text { Antibiotics/medications taken by the mother during pregnancy } \\
\text { Antibiotics/medications taken by the involved child } \\
\text { Environmental contaminants } \\
\text { Acute medical condition(s) that affect the mother during pregnancy } \\
\text { Acute medical condition(s) that affect the involved child } \\
\text { Fluoride exposure } \\
\text { None }\end{array}$ & $100 \%$ & $\begin{array}{l}65(69 \%) \\
40(43 \%) \\
21(22 \%) \\
51(54 \%) \\
42(45 \%) \\
32(34 \%) \\
16(17 \%) \\
7(7 \%) \\
3(3 \%) \\
1(1 \%)\end{array}$ & $\begin{array}{l}14(70 \%) \\
8(40 \%) \\
9(45 \%) \\
7(35 \%) \\
5(25 \%) \\
6(30 \%) \\
3(15 \%) \\
- \\
2(10 \%) \\
1(5 \%)\end{array}$ & $\begin{array}{l}51(69 \%) \\
32(43 \%) \\
12(16 \%) * \\
44(59 \%) \\
37(50 \%) \\
26(35 \%) \\
14(19 \%) \\
7(9 \%) \\
5(7 \%) \\
-\end{array}$ \\
\hline \multicolumn{5}{|l|}{ Which material do you use MOST in treating MIH molars? } \\
\hline $\begin{array}{l}\text { Amalgam } \\
\text { Composite resin } \\
\text { Flowable composite resin } \\
\text { Glass lonomer Cement } \\
\text { Compomer } \\
\text { Resin Modified Glass lonomer Cement } \\
\text { Preformed crowns }\end{array}$ & $23 \%$ & $\begin{array}{l}- \\
13(59 \%) \\
9(41 \%) \\
4(18 \%) \\
7(32 \%) \\
5(23 \%) \\
9(41 \%)\end{array}$ & $\begin{array}{l}- \\
\text { I (50\%) } \\
- \\
- \\
\text { I (50\%) } \\
\text { I (50\%) } \\
-\end{array}$ & $\begin{array}{l}- \\
12(60 \%) \\
9(45 \%) \\
4(20 \%) \\
4(20 \%) \\
4(20 \%) \\
9(45 \%)\end{array}$ \\
\hline \multicolumn{5}{|l|}{ Which factors influence your choice of restorative material? } \\
\hline $\begin{array}{l}\text { Adhesion } \\
\text { Aesthetics } \\
\text { Patient/parent preference } \\
\text { Durability } \\
\text { Remineralization potential } \\
\text { Sensitivity } \\
\text { Personal experience } \\
\text { Research findings }\end{array}$ & $23 \%$ & $\begin{array}{l}10(45 \%) \\
7(32 \%) \\
7(32 \%) \\
14(64 \%) \\
6(27 \%) \\
7(32 \%) \\
8(36 \%) \\
7(32 \%)\end{array}$ & $\begin{array}{l}\text { I (50\%) } \\
\text { I (50\%) } \\
\text { I (50\%) } \\
\text { I (50\%) } \\
\text { I (50\%) } \\
\text { I ( }(50 \%) \\
\text { 2(100\%) } \\
\text { I ( }(50 \%)\end{array}$ & $\begin{array}{l}9(45 \%) \\
6(30 \%) \\
6(30 \%) \\
13(65 \%) \\
5(25 \%) \\
6(30 \%) \\
6(30 \% \\
6(30 \%\end{array}$ \\
\hline \multicolumn{5}{|l|}{ Do you think MIH is a clinical problem? } \\
\hline & $23 \%$ & $20(91 \%)$ & I (50\%) & $19(95 \%)$ \\
\hline \multicolumn{5}{|l|}{ If yes, what do you experience problems with? } \\
\hline $\begin{array}{l}\text { Diagnosis } \\
\text { Aesthetics } \\
\text { Achieving adequate local anesthesia } \\
\text { Determining the restorative margins of affected enamel } \\
\text { Providing adequate restorations } \\
\text { Long-term success of restorations } \\
\text { Achieving patient comfort (for function, oral hygiene) }\end{array}$ & $23 \%$ & $\begin{array}{l}8(40 \%) \\
5(25 \%) \\
2(10 \%) \\
5(25 \%) \\
5(25 \%) \\
14(64 \%) \\
8(36 \%)\end{array}$ & $\begin{array}{l}- \\
- \\
- \\
- \\
- \\
2(100 \%) \\
2(100 \%)\end{array}$ & $\begin{array}{l}8(42 \%) \\
5(26 \%) \\
2(11 \%) \\
5(26 \%) \\
5(26 \%) \\
12(60 \%) \\
6(30 \%)\end{array}$ \\
\hline \multicolumn{5}{|c|}{ Would you suggest including clinical training regarding MIH in your dental course? } \\
\hline $\begin{array}{l}\text { Diagnosis } \\
\text { Etiology } \\
\text { Treatment }\end{array}$ & $96 \%$ & $\begin{array}{l}85(90 \%) \\
44(47 \%) \\
85(90 \%)\end{array}$ & $\begin{array}{l}17(85 \%) \\
11(55 \%) \\
19(95 \%)\end{array}$ & $\begin{array}{l}68(92 \%) \\
33(45 \%) \\
66(89 \%)\end{array}$ \\
\hline
\end{tabular}

Note: Significant differences between IIth and I2th semester $(P<0.05$, Chi-squared test $)$ are indicated in bold*. 
MIH patients in their practice at the training clinic on a monthly basis. In our study, the number of students who came into contact with MIH teeth every month during their internship was only $15 \%(\mathrm{n}=22)$ which was in agreement with Germany (16\%). Of the possible answers for the possible factors involved in the etiology of MIH, the majority of the students of all studies rated genetics as important. A majority of all study groups wanted the topic to be included more in their studies (73-97\%). The majority of students in all questionnaire studies (90-98\%) felt that more should be taught about diagnosing MIH. When comparing the three questionnaire studies with each other, it is interesting that the Saudi Arabian students apparently have more contact with patients with MIH, but the German and Austrian students of dentistry are more familiar with the clinical criteria for diagnosing or the clinical appearance of MIH. Both groups wished that MIH would be taught more in their clinical courses and lectures and that dealing with MIH would be practiced. In summary, it can be noted that the results from Germany and Austria are comparable. It can be assumed that this is due to the similarity of the dental curriculum, similar cultural circumstances and the fact that both studies were conducted at approximately the same time. The Saudi Arabian study was carried out 5 years earlier which is a long time in terms of the developments MIH has taken in recent years.

The answers of the students in the 11th semester often differed significantly from those of the students in the 12th semester. Especially with regard to the students' selfassessment of being able to diagnose and/or treat $\mathrm{MIH}$ patients. Only two students in the 11th semester believed there were able to diagnose and treat $\mathrm{MIH}$. On the other hand, $27 \%$ of the 12 th semester students reported their ability in diagnosing and treating $\mathrm{MIH}$ patients. The reason for this is probably the greater clinical experience of the 12th semester students in dealing with patients. In addition, the internship in pediatric dentistry only takes place in 12th semester, where the probability of encountering a patient with MIH is relatively higher. Students in the 11th semester are given preference to patients, who have caries need restorative treatment.

With regard to a comparison of the results found for Austrian students with those of dentists, it can be noted that general practitioners are also mostly unconfident about diagnosing $\mathrm{MIH}$ and have difficulty in distinguishing $\mathrm{MIH}$ from other conditions when compared to dental specialists. ${ }^{24,27,33}$ Studies have shown that these practitioners requested similarly for a training course regarding MIH in terms of aetiological, diagnostic and therapeutic fields which underlines the importance of offering opportunities to deepen the knowledge in this field.

\section{Strengths and Limitations of the Study}

One of the strengths of this study is that a validated questionnaire was used. The original version was applied in Australia, Chile and Saudi Arabia. ${ }^{21,27}$ In Germany, this questionnaire was translated and also used. ${ }^{26}$ Therefore, it is possible to generalize and compare the results found in our study for Austria with other countries.

One limitation that needs to mentioned is students putatively provide "desired" responses given them being aware that their answers were being evaluated in a study. However, the anonymity of respondents should have limited this source of bias. Another limitation of this study includes that we did not choose a nationwide design. However, the Medical University of Vienna is one of three public dental schools in Austria with the highest proportion of graduates. Nevertheless, further studies should include all dental schools in Austria as well as practicing dentists. Furthermore, the selection of students can be considered as a limitation. Randomized sampling was chosen for the whole sample and not for each semester, leading to an imbalance in the semester sizes, which could have an influence on the results.

\section{Conclusions}

MIH seems to be a topic of interest to Austrian dental students and dentists, as the majority of all respondents are in favor of deepening their knowledge regarding this topic. It is necessary to offer students opportunities to deepen their knowledge in the field of MIH both during and after their studies. The results suggest that the MIH topic should be more deeply implemented in the dental curriculum, moreover, a standardized European or international curriculum might ensure a worldwide spread of knowledge about MIH. In Vienna, the results found have already been discussed with the local curriculum commission so that the topic of MIH can be given a greater share within the theoretical and practical dental curriculum.

\section{Funding}

No funding was received.

\section{Disclosure}

Prof. Dr. Tanja Stamm reports grants, personal fees from AbbVie, Roche, Sanofi, Takeda, outside the submitted 
work. The authors report no other conflicts of interest in this work.

\section{References}

1. Kukleva MP, Petrova SG, Kondeva VK, Nihtyanova TI. Molar incisor hypomineralisation in 7-to-14-year old children in Plovdiv, Bulgaria-an epidemiologic study. Folia Med. 2008;50:71-75.

2. Jalevik B. Prevalence and diagnosis of Molar-IncisorHypomineralisation (MIH): a systematic review. Eur Arch Paediatr Dent. 2010;11(2):59-64. doi:10.1007/BF03262714

3. Garcia-Margarit M, Catala-Pizarro M, Montiel-Company JM, Almerich-Silla JM. Epidemiologic study of molar-incisor hypomineralization in 8-year-old Spanish children. Int J Paediatr Dent. 2014;24 (1):14-22. doi:10.1111/ipd.12020

4. Weerheijm KL, Jalevik B, Alaluusua S. Molar-incisor hypomineralisation. Caries Res. 2001;35(5):390-391. doi:10.1159/ 000047479

5. Allazzam SM, Alaki SM, El Meligy OA. Molar incisor hypomineralization, prevalence, and etiology. Int J Dent. 2014;2014:234508. doi: $10.1155 / 2014 / 234508$

6. Garot E, Rouas P, Somani C, Taylor GD, Wong F, Lygidakis NA. An update of the aetiological factors involved in molar incisor hypomineralisation (MIH): a systematic review and meta-analysis. Eur Arch Paediatr Dent. 2021:1-6. doi:10.1007/s40368-021-00646-x

7. Iwai T, Isomatsu Y, Iwamoto M, Tohnai I. Bisphosphonate-related enamel hypoplasia in a child with idiopathic arterial calcification of infancy. Br J Oral Maxillofac Surg. 2013;51(7):e186-e187. doi:10.1016/j.bjoms.2012.05.008

8. Jeremias F, Koruyucu M, Küchler EC, et al. Genes expressed in dental enamel development are associated with molar-incisor hypomineralization. Arch Oral Biol. 2013;58(10):1434-1442. doi:10.1016/j.archoralbio.2013.05.005

9. Jeremias F, Pierri RA, Souza JF, et al. Family-based genetic association for molar-incisor hypomineralization. Caries Res. 2016;50 (3):310-318. doi:10.1159/000445726

10. Bussaneli DG, Restrepo M, Fragelli CMB, et al. Genes regulating immune response and amelogenesis interact in increasing the susceptibility to molar-incisor hypomineralization. Caries Res. 2019;53 (2):217-227. doi:10.1159/000491644

11. Elhennawy K, Manton DJ, Crombie F, et al. Structural, mechanical and chemical evaluation of molar-incisor hypomineralization-affected enamel: a systematic review. Arch Oral Biol. 2017;83:272-281. doi:10.1016/j.archoralbio.2017.08.008

12. Elhennawy K, Schwendicke F. Managing molar-incisor hypomineralization: a systematic review. J Dent. 2016;55:16-24. doi:10.1016/j. jdent.2016.09.012

13. Weerheijm KL. Molar incisor hypomineralization (MIH): clinical presentation, aetiology and management. Dent Update. 2004;31 (1):9-12. doi:10.12968/denu.2004.31.1.9

14. Gutiérrez TV, Ortega CCB, Pérez NP, Pérez AG. Impact of molar incisor hypomineralization on oral health-related quality of life in Mexican schoolchildren. J Clin Pediatr Dent. 2019;43(5):324-330. doi:10.17796/1053-4625-43.5.4

15. Hasmun N, Lawson J, Vettore MV, Elcock C, Zaitoun H, Rodd H. Change in oral health-related quality of life following minimally invasive aesthetic treatment for children with molar incisor hypomineralisation: a prospective study. Dent J. 2018;6(4):61. doi:10.3390/ dj6040061.

16. Velandia LM, Alvarez LV, Mejia LP, Rodriguez MJ. Oral health-related quality of life in Colombian children with molar-incisor hypomineralization. Acta Odontol Latinoam. 2018;31:38-44.
17. Weerheijm KL, Duggal M, Mejare I, et al. Judgement criteria for molar incisor hypomineralisation (MIH) in epidemiologic studies: a summary of the European meeting on MIH held in Athens, 2003. Eur J Paediatr Dent. 2003;4:110-113.

18. Somani C, Taylor GD, Garot E, Rouas P, Lygidakis NA, Wong FSL. An update of treatment modalities in children and adolescents with teeth affected by molar incisor hypomineralisation (MIH): a systematic review. Eur Arch Paediatr Dent. 2021:1-26. doi:10.1007/s40368-021-00635-0

19. Lygidakis NA, Wong F, Jalevik B, Vierrou AM, Alaluusua S, Espelid I. Best clinical practice guidance for clinicians dealing with children presenting with Molar-Incisor-Hypomineralisation (MIH): an EAPD policy document. Eur Arch Paediatr Dent. 2010;11 (2):75-81. doi:10.1007/BF03262716

20. Wall A, Leith R. A questionnaire study on perception and clinical management of molar incisor hypomineralisation (MIH) by Irish dentists. Eur Arch Paediatr Dent. 2020;21(6):703-710. doi:10.1007/ s40368-020-00519-9

21. Gambetta-Tessini K, Marino R, Ghanim A, Calache H, Manton DJ. Knowledge, experience and perceptions regarding Molar-Incisor Hypomineralisation (MIH) amongst Australian and Chilean public oral health care practitioners. BMC Oral Health. 2016;16(1):75. doi:10.1186/s12903-016-0279-8

22. Serna-Munoz C, Martinez-Beneyto Y, Perez-Silva A, Poza-Pascual A, Ibanez-Lopez FJ, Ortiz-Ruiz AJ. Perception, knowledge, and attitudes towards molar incisor hypomineralization among Spanish dentists: a cross-sectional study. BMC Oral Health. 2020;20(1):260. doi:10.1186/s12903-020-01249-6

23. Gamboa GCS, Lee GHM, Ekambaram M, Yiu CKY. Knowledge, perceptions, and clinical experiences on molar incisor hypomineralization among dental care providers in Hong Kong. BMC Oral Health. 2018;18(1):217. doi:10.1186/s12903-018-0678-0

24. Kalkani M, Balmer RC, Homer RM, Day PF, Duggal MS. Molar incisor hypomineralisation: experience and perceived challenges among dentists specialising in paediatric dentistry and a group of general dental practitioners in the UK. Eur Arch Paediatr Dent. 2016;17(2):81-88. doi:10.1007/s40368-015-0209-5

25. Reaga J, Evaluating knowledge regarding Molar Incisor Hypomineralisation (MIH): a survey of dental students in Victoria, Australia., in Melbourne dental school. Melbourne: The University of Melbourne; 2016.

26. Elhennawy K, Anang M, Splieth C, et al. Knowledge, attitudes, and beliefs regarding molar incisor hypomineralization (MIH) amongst German dental students. Int J Paediatr Dent. 2020;31(4):486-495. doi:10.1111/ipd.12715

27. Silva MJ, Alhowaish L, Ghanim A, Manton DJ. Knowledge and attitudes regarding molar incisor hypomineralisation amongst Saudi Arabian dental practitioners and dental students. Eur Arch Paediatr Dent. 2016;17(4):215-222. doi:10.1007/s40368-016-0230-3

28. Crombie FA, Manton DJ, Weerheijm KL, Kilpatrick NM. Molar incisor hypomineralization: a survey of members of the Australian and New Zealand society of paediatric dentistry. Aust Dent J. 2008;53(2):160-166. doi:10.1111/j.18347819.2008.00026.x

29. Hussein AS, Ghanim AM, Abu-Hassan MI, Manton DJ. Knowledge, management and perceived barriers to treatment of molar-incisor hypomineralisation in general dental practitioners and dental nurses in Malaysia. Eur Arch Paediatr Dent. 2014;15(5):301-307. doi:10.1007/s40368-014-0115-2

30. von Elm E, Altman DG, Egger M. The Strengthening the Reporting of Observational Studies in Epidemiology (STROBE) statement: guidelines for reporting observational studies. Ann Intern Med. 2007;147(8):573. doi:10.7326/0003-4819-1478-200710160-00010 
31. Weerheijm KL, Mejare I. Molar incisor hypomineralization: a questionnaire inventory of its occurrence in member countries of the European Academy of Paediatric Dentistry (EAPD). Int $J$ Paediatr Dent. 2003;13(6):411-416. doi:10.1046/j.1365263x.2003.00498.x

32. Tagelsir A, Dean JA, Eckert GJ, Martinez-Mier EA. U.S. pediatric dentists' perception of molar incisor hypomineralization. Pediatr Dent. 2018;40:272-278.
33. Alanzi A, Faridoun A, Kavvadia K, Ghanim A. Dentists' perception, knowledge, and clinical management of molar-incisorhypomineralisation in Kuwait: a cross-sectional study. BMC Oral Health. 2018;18(1):34. doi:10.1186/s12903-018-0498-2

\section{Publish your work in this journal}

The Journal of Multidisciplinary Healthcare is an international, peerreviewed open-access journal that aims to represent and publish research in healthcare areas delivered by practitioners of different disciplines. This includes studies and reviews conducted by multidisciplinary teams as well as research which evaluates the results or conduct of such teams or healthcare processes in general. The journal covers a very wide range of areas and welcomes submissions from practitioners at all levels, from all over the world. The manuscript management system is completely online and includes a very quick and fair peer-review system. Visit http://www.dovepress.com/testimonials. php to read real quotes from published authors. 